\title{
LA FUENTE DE LA ANTIGUA PLAZA DEL SANTUARIO DE GUADALUPE
}

\section{ROGELIO RUIZ GOMAR}

La vistosa fuente que por poco más de doscientos años luciera en la plaza ubicada a un costado de la antigua basílica de la Virgen de Guadalupe fue desmantelada y removida de su sitio en una fecha cercana al año de 1975, en que se iniciaron las obras que culminarían con la erección de la nueva basílica.

Esta remoción era ya un motivo de preocupación por la suerte incierta a que se le sentenciaba, pero lo que resulta lamentable en verdad y provoca indignación es que no se haya encontrado otra salida que la de desarmarla y condenarla al completo estado de abandono en que permanece hasta hoy dia: arrumbada en calidad de desecho junto a otros materiales en unos terrenos pertenecientes al santuario que se hallan a espaldas del cerro del Tepeyac, y a los cuales se tiene acceso por la actual calle de Cantera. Triste final para una fuente que cumplió satisfactoriamente con su doble cometido de dotar de agua al vecindario y servir de ornato al sitio. Desenlace vergonzoso, pero en buena manera previsible en un país que, como el nuestro, no se ha caracterizado precisamente por su interés y respeto hacia lo que constituye su patrimonio histórico-artístico.

Cierto que ya el paso del tiempo había dejado su huella en las piedras que la conformaban, pero en modo alguno puede ser esgrimido dicho deterioro como argumento para intentar justificar su retiro, y mucho menos como razón que nos exima de los cargos que quizá algún días nos levanten las generaciones venideras, así por los inevitables daños que se le ocasionaron cuando se procedió a desmantelarla, cuanto por los innecesarios perjuicios que van a resultarle del actual estado de desamparo.

A esta fuente y plaza se refería Juan de Viera, el cronista de la ciudad de México en el siglo XVIII, al asentar lo siguiente:

Tiene la Plaza casi enmedio una hermosísima fuente, bastante grande y amplia, que sólo ella da con sus aguas abasto a todo el vecindario de la Villa. Su material es de una cantera rubia color de nácar y en el centro tiene una bien formada columna que sirve de pedestal, sobre nubes de ángeles, a la imagen sacratísima de Nuestra Señora formada de talla a perfección del cincel. ${ }^{\perp}$

1 Juan de Viera, Compendiosa narración de la ciudad de México, prol y notas de Gonzalo Obtegón; México, Editorial Guarania, 1952, pp. 81.82. 
La plaza se abría al costado poniente de la antigua basílica y, como es lógico suponer, vivió una serie de transformaciones con el correr de los años antes de desaparecer. Así, en el año de 1886 fue objeto de un completo programa de remodelación que la convirtió en el Jardín Juárez -nombre con que se le conoció hasta mediados del presente siglo- en el centro del cual descollaba la fuente que nos ocupa, y para cuyo ornato se encargaron a Nueva York cuatro estatuas de hierro que representaban a las estaciones, varios macetones, también de hierro, en pedestales de piedra, y treinta y dos bancas que fueron diseminadas hábilmente por toda su extensión. ${ }^{2}$

Mas, llegó el día en que el creciente desarrollo urbano y las necesidades de la vida moderna se hicieron presentes también en esta apacible zona del norte de la ciudad y hubo que suprimir dicho jardín, a fin de dar paso a la construcción de la altiva y monumental Plaza de las Américas que fuera solemnemente bendecida el 20 de noviembre de 1954. Y, si bien la fuente dieciochesca que nos ocupa no encontró cabida en la nueva plaza, se tuvo, sin embargo, el buen juicio de no suprimirla, y sólo se le desplazó unos metros a una zona jardinada fuera del perímetro de aquélla. ${ }^{3}$ Fue así que pudo subsistir unos años más; hasta que, como se ha apuntado, ante la necesidad de disponer de mayores espacios al ponerse en marcha el proyecto para la contrucción de la nueva basílica, se tuvo a bien suprimirla definitivamente.

Con ser tan grave la decisión, a nadie preocupó. Pareciera que de tanto asistir a la inmolación de páginas de nuestra historia y de nuestro arte en aras del progreso, la profanación fuese un paso no sólo lícito, sino natural. Pero no está fuera de lugar recordar que todos somos responsables ante las futuras generaciones del rico legado cultural que ha llegado a nosotros, y que en este sentido, todos, apoltronados en nuestra cómoda pasividad de testigos mudos, nos convertimos en cómplices de semejantes atentados.

Empero, si hemos quedado impedidos de la contemplación de la fuente, podemos, al menos, adentrarnos un poco en su historia, gracias a un

2 Vid. Juan de la Torre, La Villa de Guadalupe, México, 1887, pp. 9-10. El Presbítero Jesús García Gutiétrez ("El Acueducto de Guadalupe", en La Rosa del Tepeyac, Año III, México, 8 de agosto de 1921) asentó que dicho jardín fue construido "enfrente de las que fueron casas de los capellanes del Santuatio", y que para ese entonces (1921, formaban las casas municipales.

3 Tal y como señalara Manuel Romero de Terretos, se le ubicó en una plazoleta, frente a una de las entradas de la moderna y amplísima plaza de la Basílica, donde, añadiera, quizá luciera mejor que en su emplazamiento anterior; vid Fuentes virreinales, México, UNAM, IIE, 1966, p 13 
traslado del contrato que se concertó para su construcción, mismo que se encuentra entre otros no menos importantes papeles relativos a la Villa de Guadalupe en el Archivo General del Departamento del Distrito Federal. ${ }^{4}$

En el estudio en que me ocupé del acueducto que se construyó a mediados del siglo xviı para suministrar el vital líquido a la población y santuario de Guadalupe, adelanté los datos más significativos contenidos en dicho contrato; ${ }^{5}$ pero dada la importancia del monumento en sí, y de la información expresada en aquél, es que he creído conveniente dedicar unas líneas para atender en forma exclusiva el asunto de la fuente en cuestión.

Por dicho traslado sabemos que la fuente fue construída entre los meses de marzo y noviembre de 1752 , por un maestro cantero vecino de la villa de nombre Antonio Rodríguez, conforme al plano o montea que se le entregó; que al igual que el acueducto al que hemos hecho referencia, fue fabricada con cantera sacada de los cerros vecinos; que tuvo un costo de 2,400 pesos y que fue llevada a cabo bajo la supervisión de Manuel Álvarez, a la sazón "maestro mayor de la ciudad de México".

Sin embargo, la importancia de dicho traslado va más allá de proporcionar el nombre de su autor material y el costo de la misma, toda vez que ilustra tanto sobre aspectos interesantes de su proceso constructivo como de los requerimientos inherentes a una obra de esta naturaleza, amén de otros detalles curiosos que ayudan a entender el marco histórico propio del momento en que fue concebida.

Pero antes de entrar en materia, convendría dejar establecidos algunos antecedentes. Para la segunda mitad del siglo XVIII el pueblo de Tepeaquilla o de Santa María de Guadalupe, estaba lejos aún de ser una población importante y carecía de agua potable. Con el propósito de solucionar las incomodidades que de esto se derivaban para los vecinos y peregrinos que concurrían al santuario erigido a la Virgen al pie del cerro del Tepeyac - habida cuenta de que no disponían mas que de las fétidas aguas del lago de Texcoco, en las inmediaciones, y de las turbias del río que pasaba frente al santuario, llamado por eso río de Guadalupe-,

\footnotetext{
${ }^{4}$ Archivo General del Departamento del Distrito Federal Guadalupe Hidalgo, 17531778, fs, 205.207. Este importante acervo ha sido incorporado al Archivo Histórico de la Ciudad de México. El contrato fue redactado ante el esctibano Juan José de Zarazúa, escribano del cual no se conserva nada en el Archivo General de Notarías de la ciudad de México. Ver Documento 1, en este trabajo.

${ }^{5}$ Rogelio Ruiz Gomar, "El Acueducto de Guadalupe", en Estudios acerca del arte nowobispano. Homenaje a Elisa Vargas Lugo, México, UNAM, 1983, pp. 142-143
} 
desde mediados de esa centuria se habían efectuado varios intentos para introducir el vital líquido desde otros sitios; correspondió a fray Payo Enríquez de Rivera, arzobispo y virrey de la Nueva España, ser el primero en dotar a dicha población y santuario con las aguas obtenidas desde el río de Tlanepantla, a más de dos leguas de distancia, al costear la construcción de una atarjea casi a flor de tierra y de una fuentecilla que quedó situada enfrente de la puerta principal del templo, ${ }^{6}$ la cual fue estrenada el 12 de diciembre del año de 1678 , tal y como puntualmente recogió Antonio de Robles en su Diario de sucesos notables. 'Mas, como los hacendados de las inmediaciones empezaron a desviar el agua para su propio provecho y la poca que llegaba a su destino resultaba insuficiente para satisfacer las necesidades de los vecinos, en poco tiempo la atarjea quedó inutilizada y la fuente abandonada por los cantareros, lavanderas y público en general, que se vió obligado de nueva cuenta a acudir diariamente al río de Guadalupe. ${ }^{8}$ Para 1713 se pudo comprobar que la atarjea se hallaba "quebrada y derrumbada en muchas partes", y su reparo fue evaluado en 8,306 pesos. ${ }^{9}$ Se trató de obligar a dichos hacendados a buscar solución al problema y a que aceptaran prorratearse los costos que se derivaran del reparo; pero en virtud de la merced de un surco de agua que fue concedido al siguiente año a don Blás López de Aragón, arrendatario de la hacienda de Santa Ana, recayó en éste gran parte de la responsabilidad de ver por el mantenimiento de aquélla y el suministro del vital líquido a la población de Guadalupe. ${ }^{10}$ Empero, como pasaban los años y esta población continuaba padeciendo por la falta de agua, en 1728 el virrey Marqués de Casa Fuerte ordenó la construcción de una nueva atarjea. La dirección de la obra fue confiada a fray Juan de Dios de Ribera, pero por "haber salido errada" quedó sin concluir y sin efecto."

Esta situación se mantuvo hasta el año de 1742 en que José de Lizardi y Valle, mayordomo y tesorero del santuario, retomó el proyecto y se dio a la tarea de construir el nuevo acueducto. Una vez hecha la demarcación

'Br. José López de Avilés. Debido respeto de agradecimiento leal a los beneficios becbos en México por... D. Fr. Payo Enríquez de Ribera, México, 1684, p 54 . A esta fuente es a la que hace referencia el plano de Santa Isabel Tola levantado en 1794 pot el Pbro., José Mariano Alarcón, en las notas explicativas, cuando en la letra "J" apun" ta: "Fuente antigua, al presente sólo vestigios".

"Antonio de Robles. Diario de sucesos notables, 2a, ed. t. I, México, Ed Porrúa, p. 254: "Lunes 12, corrió el agua en la pila de Guadalupe por orden y costo de S.E."

8 Delfina López Sarrelangue, Una villa mexicana en el siglo XVIII, México, UNAM, p. 85 .

${ }^{*}$ Atchivo General de la Nación Historia, 114, exp. 1, f 9-9v"

10 Rogelio Ruiz Gomat, op. cit, pp. 125-126.

11 Ibidem, p. 127 
del paraje por donde habría de construirse, realizada por los arquitectos Manuel Álvarez y Miguel Custodio Durán, ${ }^{12}$ se puso la primera piedra el 20 de junio de 1743. La obra fue terminada el 30 de marzo de 1751, fecha en que se acabó la caja repartidora; sin embargo, sería hasta el 7 de julio de ese mismo año en que se viera correr de nueva cuenta el agua en la población de Guadalupe. ${ }^{13}$

Así las cosas, una vez que hubo llegado a feliz término la construcción del acueducto, el oidor Domingo de Trespalacios y Escandón, superintendente de las obras, consideró llegado el momento de iniciar la fábrica de una fuente en la plaza principal, debido a que tanto los miembros del cabildo como los vecinos continuaban acarreando el agua desde la mencionada caja o pila construída al final de aquél, y sin dilación dispuso todo lo necesario y conducente para tal fin.

Por el traslado del contrato al que hemos aludido, sabemos que el 21 de marzo del año de 1752, comparecieron en la ciudad de México ante el escribano Juan José de Zarazúa, el maestro cantero Antonio Rodríguez, vecino de la villa de Guadalupe, pero residente en la ciudad de México, y su fiador el hilador de seda Jerónimo Espinosa, por una parte, y el tesorero y mayordomo del santuario, el citado José de Lizardi y Valle, por la otra, para ultimar los detalles y condiciones que privarían en la construcción de dicha fuente. El primero aceptó hacerse cargo de la construcción de la misma, según el mapa o montea delineado por disposición del mencionado Domingo de Trespalacios, que en ese momento se le entregó ${ }^{14}$ y se comprometió a tenerla debidamente terminada en un plano de seis meses que empezarian a correr desde ese mismo dia. ${ }^{15}$ El precio concertado por las partes para la fábrica fue de 2,400 pesos. $^{16}$

${ }^{12}$ AGN. Tierras, 641, exp. 5, f 6.

${ }^{13}$ Vid. Ignacio Carrillo y Pérez. Pensil Americano. ., México, 1797. Este acueducto, con un trayecto de poco más de 10 kilómetros (12,133 varas según unos autores, 12,287 según otros) se consetva casi completo, con sus reposadetas y pila, si bien algunos tramos del mismo se encuentran en estado ruinoso. La caja ha sido remozada en fecha reciente y se localiza en la confluencia de las actuales calles de Cantera y Morelos, a un costado del Parque de la Hispanidad.

14 Desafortunadamente no se menciona al autor del proyecto, pero no sería difícil que hubiese sido ejecutado pot el citado Manuel Álvarez, cuanto más que, como se ha apuntado, había sido (en sti calidad de "maestro mayor de la ciudad de México") el responsable de las obras en la conducción del agua y fue designado supervisor de la fábrica de esta fuente.

${ }^{15}$ Según Juan de la Torre (op. cit., p. 10) las obras se iniciaron hasta el 15 de junio de ese mismo año.

${ }^{16} \mathrm{Vid}$. infra nota 4, f. 207. Prefiero atenerme a esta información, pero acaso haya una confusión o un ettor, pues es el caso de que en otro documento (AGDDF, Guadalupe Hidalgo, 1759-1781, leg. 26, exp. 2042, s/f) se lee que dicha fuente tuvo un costo 
Sin duda uno de los puntos más interesantes del contrato es el que alude a la naturaleza de la obra y al modo en que debía cotizarse su construcción, pues por ser ésta una obra que no sólo demandaba "uniforme igualdad en sus partes para la debida proporción", sino que era preciso que todas y cada una de las muchas piezas que la conformaban ajustaran en las uniones "con tal arreglo que no se advirtiera la menor imperfección" - como que de ello dependía la permanente solidez-, se encontró que lo más adecuado era el de convenir en un precio global, esto es pactar o ajustar el trabajo por destajo, con la correspondiente causión de su afiance, ya que de no procederse así, de emprenderse la labor de acuerdo a la manera regular de cotizar la obra por piezas, siendo estas en número tan crecido, se corría el riesgo de que "si al tiempo de asentarse [se] descubrieran los defectos de malos ajustes, $u$ otros que los dejaran inútiles, se aventuraba el valor de la piedra y precio de su manufactura, con otros consecuentes costos".

Como ya se ha apuntado, Antonio Rodríguez se comprometió a dar "en el todo perfectamente concluída la referida fuente por el precio de dos mil pesos y cuatrocientos pesos" en un plazo de seis meses que se comenzarían a contar desde ese mismo día, pero habría que añadir que la paga a los entalladores y estatuarios correría por cuenta del propio Rodríguez.

De acuerdo a un primer planteamiento, éste recibiría 92 pesos y 2 tomines en cada una de las 26 semanas que conformaban el plazo, y en la última un real más. Sin embargo, como solicitara y obtuviera en ese momento del mayordomo y tesorero del santuario 400 pesos adelantados, para "suplementos a los oficiales", se acordó que no recibiría nada en las primeras cuatro semanas, y que para la quinta sólo se le entregarían 31 pesos.

El citado cantero se comprometía a labrar y poner todo esmero en cada una de las piezas y partes de la fuente, "así en el brocal. . como en las estatuas, pedestales y demás follaje, adorno y simetría del pilarejo”, sin omitir alguna de todas de que se componía.

Tocante a los materiales, se estipuló que toda la piedra del brocal, pilarejo y escalones debería de ser "del cerro que nombran del Chiquihuite", y de acuerdo a las medidas y tamaños que el propio Rodriguez fuera solicitando. Dicho material le sería entregado a toda su satisfacción en el taller, pero a fin de que no se suspendiera la manufactura, debería avisar

de 8,998 pesos, monto que es el que recoge Manuel Romero de Terreros (Los Actieductos de México en la bistoria y en el arte, México, UNAM, 1949, p. 139), y que no concuerda tampoco con las cantidades que al mismo respecto proporcionan Juan de la Torre (op cit, p 10), de 9,057 pesos 2 tomines 9 gramos, y Delfina López Sarrelangue (op cit., p. 52), de tan sólo 905 pesos 7 tomines y 9 gtamos. 
DOI: http://dx.doi.org/10.22201/iie.18703062e.1986.57.1338

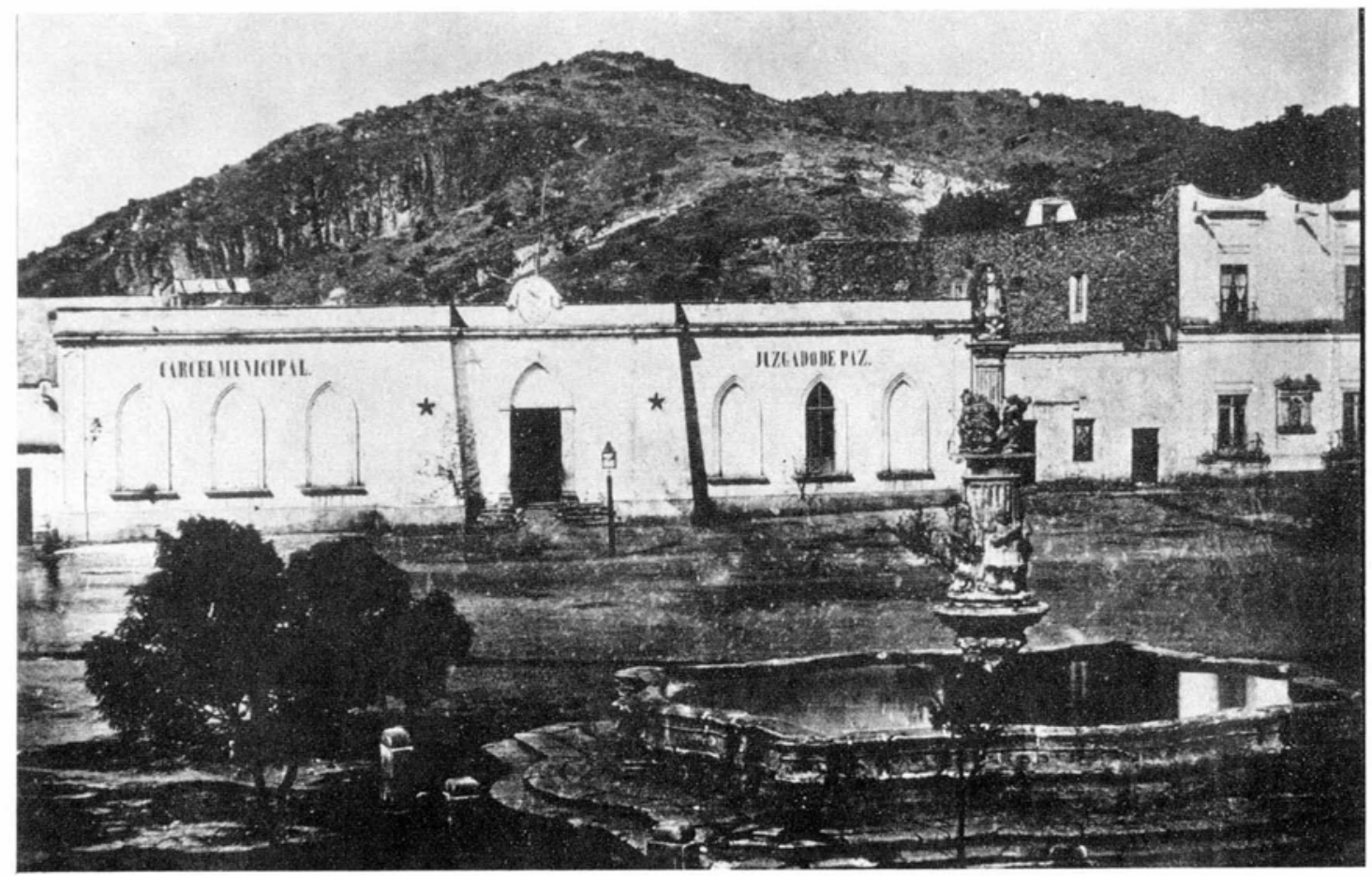

Figura 1. Aspecto de la plaza y de la fuente a fines del siglo pasado. Foto INAH. 
DOI: http://dx.doi.org/10.22201/iie.18703062e.1986.57.1338

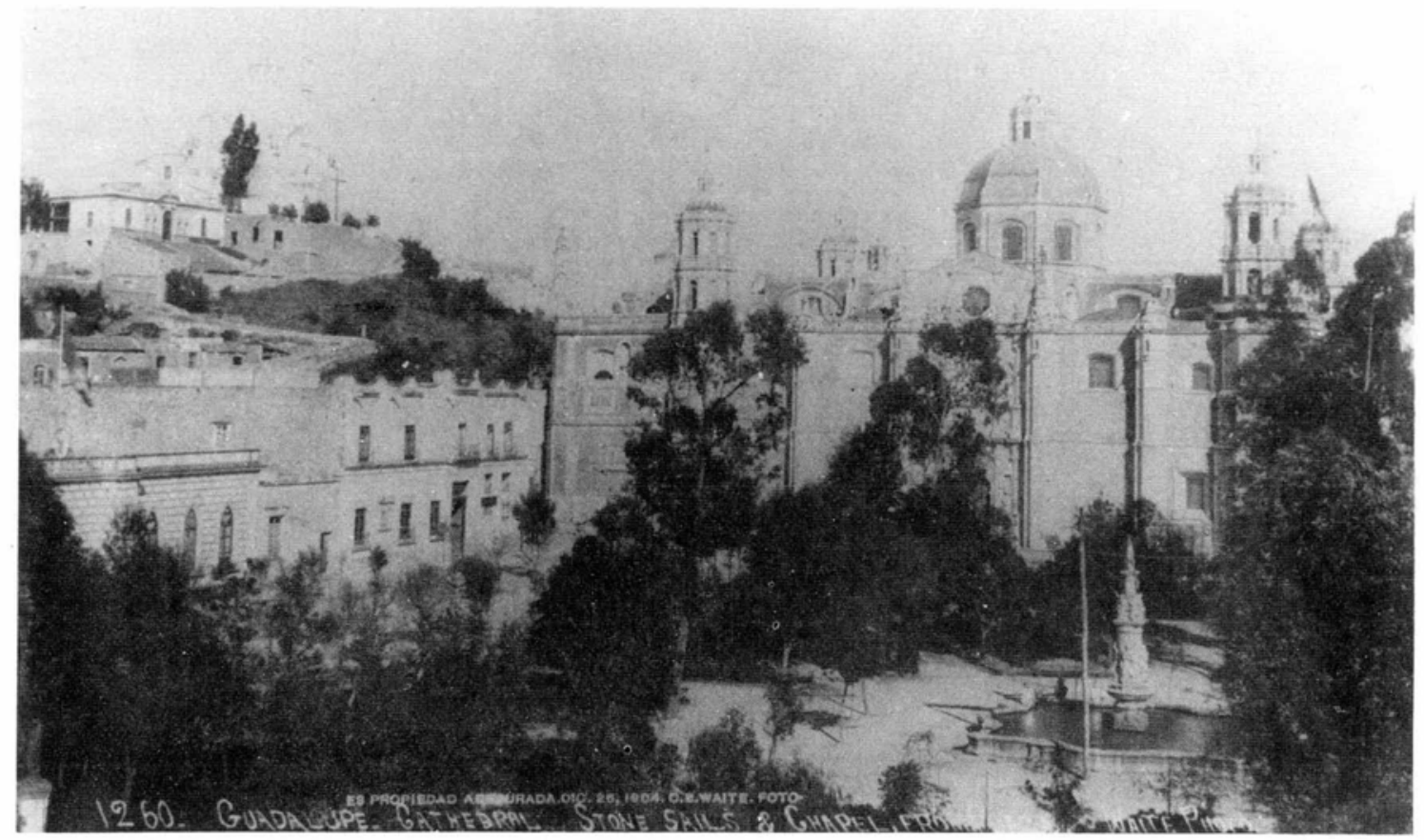

Figura 2. Vista de la plaza en el año de 1904, registrada por C.B. Waite. Foto INAH. 


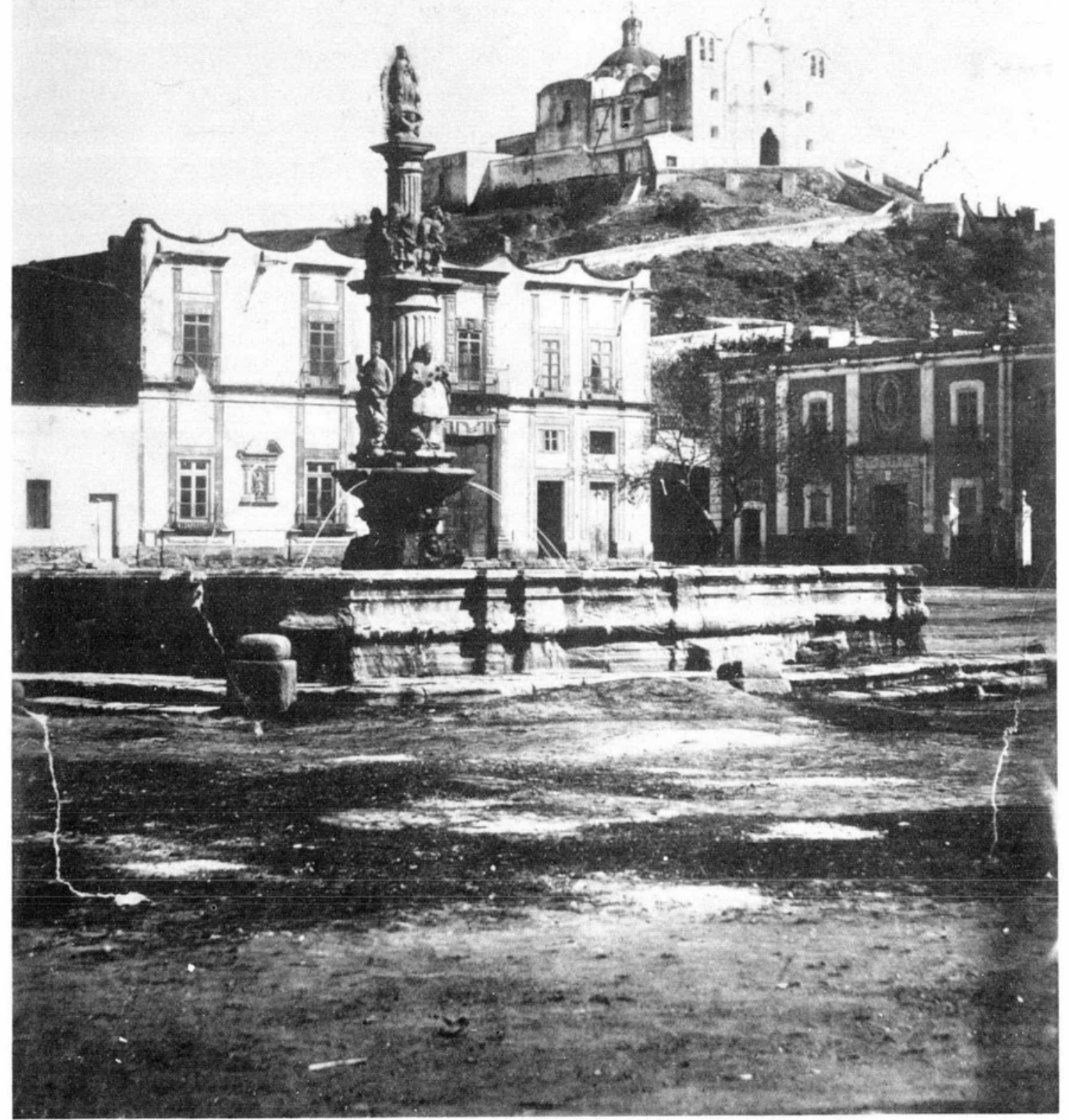

Figura 3. La fuente hacia la década de los años treinta del presente siglo. Foto INAH. 
DOI: http://dx.doi.org/10.22201/iie.18703062e.1986.57.1338

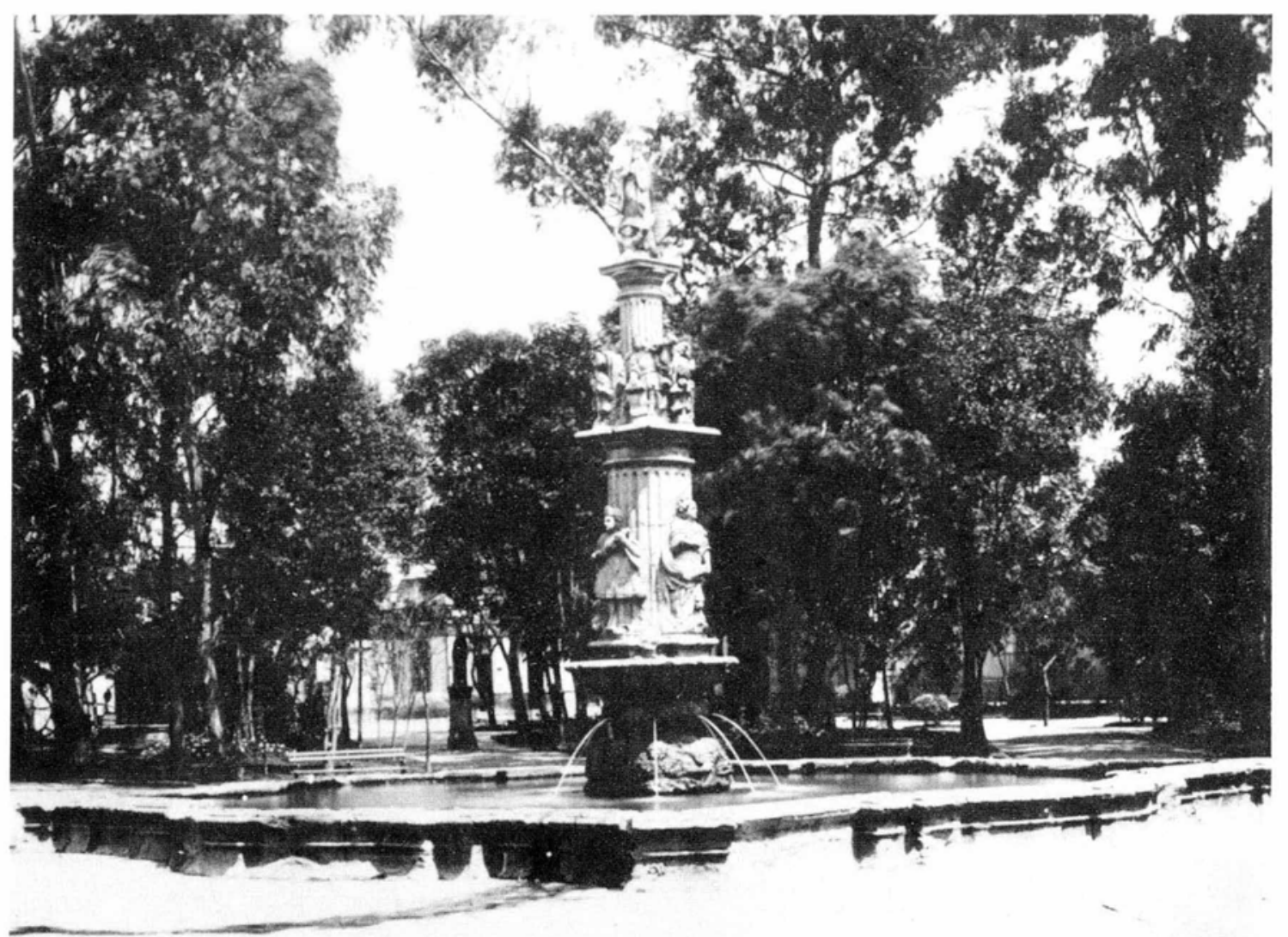

Figura 4. Aspecto de la plaza y la fuente a mediados de este siglo. Foto INAH. 
y pedir el que fuere necesitando con el tiempo que considerara pertinente, toda vez que debería dar cumplimiento a la obra dentro del plazo fijado, y sólo se le disculparía cuando "con evidencia y sin dolo" hubiese dejado de recibir lo que él hubiere pedido.

Si después de labrar las piedras por él escogidas y seleccionadas se descubriere en lo interior de ellas alguna veta o imperfección, por mínima que ésta fuere, y que a juicio del maestro Álvarez ello redundara en perjuicio de la obra, no se le habrían de recibir, y tendría que volverlas a labrar a su costa, erogando también lo que resultara de su corte y conducción. Para protegerse le quedaba el recurso de no recibir las que le pareciesen imperfectas o poco útiles, a sabiendas de que las que de ese modo fuese desechando, otras tantas debería volver a pedir con la mayor premura, a fin de no interrumpir la obra por falta de materiales.

Debería poner particular cuidado "en todos y cada uno de los ajustes, engargolando y buscando los enlaces y amarres de las piedras en todo rigor del arte", sin acomodar piezas pequeñas ni suplir los defectos con semejantes; celo que Rodríguez debería observar no sólo cuando el trabajo en el taller, sino extender al tiempo en que fuesen asentadas las partes por el albañil, y ello tanto para las piedras de la fuente y pilarejo, como para las de las gradas o enlosado, que deberían ser de la misma calidad y con igual perfección.

La última cláusula del contrato dice a la letra:

Y finalmente, que donde ha de hacer el otorgante la entrega, es en el lugar en que se está concluyendo la fuente como propio para su recibo, $y$ en el que se han de ir reconociendo los defectos, para que enmiende los que lo permitieren o labre de nuevo las que no se le admitiesen;...

Carecemos de noticias sobre el desarrollo de la obra, pero todo hace suponer que se llevó a cabo sin ningún contratiempo, pues la fuente pudo ser estrenada el 24 de noviembre de ese mismo año, día en que con solemne ceremonía de acción de gracias, se introdujo el agua en ella. ${ }^{17}$ Días más

${ }^{17}$ AGDDF. Guadalupe Hidalgo, 1759-1781, leg. 26, exp. 2042, s/f.,: "Memoria de gastos para la bendición de la pila". Para tal ocasión se enlista la compra de bizcochos, chocolates, dulces, soletas, nieve, flores y cohetes. Es conveniente puntualizar que sobre el particular se equivocó Ignacio Carrillo y Pérez (op cit) al señalar la fecha del 7 de julio de 1751, y junto con él todos los autotes que le siguen, ya que, como hemos apuntado, ésta corresponde a la de la introducción del agua en la caja repartidora, y no a la de la fuente que nos ocupa. 
tarde el maestro cantero habría de extender un recibo en el que se daba por servido y bien pagado. ${ }^{18}$

Respecto del tal Antonio Rodríguez nada hemos podido averiguar, salvo que, como se asienta en el documento que hemos glosado, era vecino de la villa de Guadalupe pero residía en la ciudad de México. ${ }^{19}$ Dos de los tres sujetos que aparecen como testigos en el contrato también eran "vecinos de dicho santuario": Ventura de Arellano y Francisco de Torres. El primero figuró como subrestante del arquitecto Manuel Álvarez durante la construcción del acueducto, y a partir del año de 1763 fue designado "guarda principal de la cañería". El segundo, creemos que no es otro que el que llegaría a ser el más importante arquitecto de la segunda mitad del siglo XVIII en la Nueva España: Francisco Guerrero y Torres, quien también aparece como testigo en el recibo que otorgó Rodríguez, por más que, curiosamente, se le registre con los apellidos invertidos: Francisco de Torres y Guerrero.

Tan familiar y conocida juzgó Manuel Romero de Terreros que debía de resultar la fuente para todos, vecinos y visitantes del santuario, que de plano asentó que era "innecesario intentar describirla". ${ }^{20}$ Pero como conforme pasa el tiempo desde que fue retirada, va siendo más vago el recuerdo de la misma, y mayor el número de gentes que no la alcanzaron a conocer, no estará de más recordar cómo era.

Contaba con un brocal bastante amplio y fuertemente moldurado, que medía casi ocho metros y medio de diámetro; ${ }^{21}$ acorde al gusto barroco del tiempo, su planta mixtilínea resultaba excesivamente movida, con entrantes y salientes que la hacían adoptar un vago perfil de estrella. ${ }^{22}$ En el medio, sobre una base ricamente labrada se erguía con ligereza una colum-

18 Ver Documento 2, al final de este trabajo.

19 Aunque la semejanza en el nombre y la cercanía de las fechas hagan bastante tentadora la relación de éste con Mariano Antonio Rodríguez, hijo del célebre arquitecto gaditano Lorenzo Rodríguez, creemos que no existe ninguna vinculación entre los dos. De este último sabemos que para 1739 apenas frisaba en los 14 años y se le pensaba destinar a la carrera eclesiástica. Vid Eduardo Báez Macías, "El testamento de José Miguel Rivera Saravia, arquitecto del siglo XVIII", en Anales del Instituto de Investigaciones Estéticas, vol XIII, núm. 46, México, UNAM, 1976, p. 163.

${ }^{20}$ Manuel Romero de Terreros, Fuentes..., p. 12.

21 Vid. Francisco Fernández del Castillo et al, México y la Guadalupana, México, 1931, p. 72, y Alfonso Marcué González, Guadalupe Guía del visitante, Cuernavaca, Ed. Juan Diego, 1955, p. 45 .

${ }^{22} \mathrm{~T}$ al y como se puede constatar en base a fotografias tomadas a la fuente en distin. tos tiempos, los pequeños desniveles de su base o escalones, fueron quedando ocultos bajo la tierra; por otra parte, tal parece que para mediados del presente siglo se le cambió el brocal, al cual, si bien se le conservó lo movido de su planta, se le imprimió una molduración más plana y rectilínea. 
na dividida en dos tramos, o mejor aún, dos columnas de corto fuste acanalado y capitel compuesto, una encima de la otra. Alrededor de la inferior estaban cuatro figuras taliadas en relieve que representaban a las cuatro partes del mundo: Europa, Asia, Africa y América; ${ }^{23}$ en tanto que la superior, de menor tamaño y más delgada, estaba adornada con cuatro ángeles trompeteros que, ataviados con amplios mantos de barroco drapeado, convocaban a las multitudes de los cuatro puntos cardinales a venerar a la augusta Virgen de Guadalupe, cuya imagen ocupaba la cúspide del pedestal, como corona y remate del mismo. Cabe apuntar que la imagen de la Guadalupana estuvo originalmente destinada para adorno de la portada de la sala capitular y sacristía del santuario, mas como en ese lugar se había colocado la imagen que don Domingo de Trespalacios había dispuesto para la caja de agua, se decidió reservar a aquélla para la fuente. ${ }^{24}$

El presbítero Jesús García Gutiérrez comentaría en 1921 que el tiempo, en complicidad con los encargados de su conservación, habían ocasionado daños a la fuente, y añadía que, pese a haberse dicho que se le iba a restaurar, no se le había hecho nada en ese sentido. ${ }^{25}$

Por este testimonio vemos que la indiferencia para con la fuente viene de lejos. Y ya sabemos que en lugar de restaurarla se optó por retirarla definitivamente hará unos pocos años, dando con ello muestra del escaso respeto por el monumento y una falta total de imaginación, pues en lugar de incluirlo dentro del proyecto para la construcción de la nueva basílica, o, en el peor de los casos, buscarle acomodo dentro del entorno natural -entendido éste no necesariamente el área del santuario y sus anexos, sino lo que hasta el día de hoy sigue siendo conocido como la Villa de Guadalupe-,${ }^{26}$ se le conminó a ser desarmado, sentenciándolo punto menos que al olvido e indefectible destrucción, pues, como era de esperarse, ya nadie volvió a ocuparse de él; y no se necesita ser profeta para asegurar que en tal estado de abandono habrá de permanecer por tiempo indefinido, toda vez que nadie parece preocuparse por su destino ni existe algún proyecto que contemple en plazo próximo su rehabilitación.

${ }^{23}$ Figuras alegóricas que Juan de la Torre no entendió, pues vio en ellas "guerreros aztecas" (op. cit,, p. 10).

${ }^{24}$ AGDDF, Guadalupe Hidalgo, 1759-1781, leg. 26, exp. 2039, s/f.

${ }^{25}$ Vid supra, nota 2, p. 160.

${ }^{26}$ Nombre con que se sigue designando a esa locación que por Real Célula del 18 de diciembre de 1733 fue elevada a la categoría de "villa" - por más que la erección no se verificó sino hasta mediados de esa centuria-, que luego, el 12 de febrero de 1828 fue elevada al rango de "ciudad" con el nombre de Guadalupe Hidalgo, y que desde 1931 fue reducida a un bartio o colonia inmetsa en el Distrito Federal, dentro de la Delegación Gustavo A. Madero. 
Somos conscientes de que todo barrio, colonia, pueblo o ciudad es un organismo vivo, en constante crecimiento y mutación. No estamos en contra de las mejoras materiales que trae aparejadas el progreso y el legítimo afán de modernidad; pero no podemos menos que manifestar nuestra crecida indignación contra la absoluta insensibilidad e indiferencia que para con nuestro acervo histórico-artístico evidenciaron en este caso tanto las autoridades civiles como eclesiásticas, al no encontrar $\rightarrow$ o no querer buscar- otra solución mejor que retirar la fuente, sin importarles que con ello se alterara la fisonomia urbana del sitio, se suprimiera un monumento significativo por sí y por su conexión con el sitio, y se privara a los vecinos $\mathrm{y}$ visitantes del deleite y sano esparcimiento que aquélla proporcionaba.

Sería una necedad de nuestra parte el pretender negar o ignorar la serie de mejoras que en distintos órdenes han resultado de las obras de remodelación que ha vivido este importante e histórico lugar desde la década de los cincuentas, tanto para los habitantes de la zona como para los numerosos visitantes que afluyen incesantemente al santuario. Cierto, además, que no es tarea fácil buscar acomodo a una fuente de brocal de regulares dimensiones como es el de la que nos ocupa, y no se nos escapan los arduos problemas de mantenimiento y cuidado que plantea una fuente en un lugar público, máxime en una ciudad - y delegación política- cuyos habitantes no se distinguen precisamente por su actividad de conservación y limpieza para con los monumentos. Problemas de idiosincracia y de educación que no hemos podido superar.

Con todo, nos queda la impresión de que el caso fue manejado con poco respeto y nula imaginación. Pues ¿no podría engalanar la fuente en cuestión alguna de las plazas o jardines con que la Delegación Gustavo A. Madero ha regalado a los vecinos de la zona, incluyendo el Parque de la Hispanidad que fuera inaugurado por los reyes de España? Acaso se arguiirá que la multicitada fuente no era ni con mucho un monumento excepcional o importante desde el punto de vista artístico y que ya se encontraba en mal estado de conservación cuando se procedió a su remoción. Mãas lo cierto es que la obra sí poseía una innegable calidad y belleza, y aunque efectivamente exhibía cierto deterioro, creemos que no era éste tan grave como para no permitir una restauración. Empero, independientemente de su valor artístico y de su estado de conservación, creemos que lo que debería de haber prevalecido en este caso, es que, en otro orden de valores, se trataba de una pieza intimamente ligada con la historia del sitio. Ignorar esto implicó desconocer su razón de ser y no tomar en cuenta las circunscias históricas que le dieron forma. $Y$ es que esta fuente fue la obra material, el logro tangible, concreto, con que se dio solución al requerimiento 
de agua potable para los miembros del cabildo y vecinos del santuario; pero no menos cierto es que también a través de ella era posible atisbar algo sobre los esfuerzos, las ideas, los mecanismos operacionales, preferencias estéticas y afanes religiosos de la comunidad a la que sirvió y de la sociedad que le dio forma.

Por todo lo anterior, y por tratarse de una de las escasísimas obras que de esta índole están documentadas — con fecha, costo y autor-, es que sería de desear que, en una labor conjunta de las autoridades civiles y eclesiásticas competentes, la fuente en cuestión fuese rescatada del ignominioso estado en que se encuentra y, tras un merecido proceso de restauración, pudiese ser rehabilitada para bien de la zona, de la ciudad y de nuestro patrimonio cultural.

Documento 1. AGDDF. Guadalupe Hidalgo. Caja 7: 1753-1778, leg. 31. exp. 2221, f. 205-207.

En la ciudad de México a veintiuno de marzo de 1752, ante mi el escribano y testigos, Antonio Rodríguez, maestro de cantero, vecino de la villa y santuario de Nuestra Señora de Guadalupe, residente en esta ciudad, a quien doy fe conozco, como principal obligado, y don Gerónimo Espinosa, maestro hilador de seda, vecino de ella como su fiador y llano pagador en que (a satisfacción del señor canónigo más antiguo de la insigne Real Iglesia Colegiata parroquial de dicho santuario don José de Lizardi y Valle, como Mayordomo Tesorero de sus propios y rentas) desde luego se constituye, haciendo como hace de causa y negocio ajeno suyo propio para que contra dicho principal no proceda, ni se haga diligencia ni exención alguna de fuero y derecho necesaria, cuyo beneficio expresamente renuncia; en cuya consecuencia ambos juntos de mancomún a voz de uno y cada uno de por sí, y por el todo insolidum, con renunciación de la ley Duobus res de vendi y la auténtica presente códice de fide jiesoribus (sic), y las demás leyes, fueros y derechos de la mancomunidad, división y exención como en ellas se contiene $=$

Dixeron que, por cuanto el señor don Domingo de Trespalacios y Escandón, caballero de la orden de Santiago, del Consejo de su Magestad, su oidor en la Real Audiencia de esta Nueva España, como superintendente director de la targea nuevamente construída para la provición del referido santuario, tiene resuelto el que por estar ésta perfectamente concluída, se dispusiesen todas las obras necesarias y conducentes para el surtimiento de la fuente principal, y estando ya en estado de que ésta se 
construya, conforme al mapa o montea que de orden de su señoría se delineó, haciéndose el cargo de que componiéndose de muchas piezas y que todas y cada una demandan no sólo la uniforme igualdad en sus partes para la debida proporción, sino el que se reduzgan (sic), abengan y ajusten en las uniones, travamentos y enlaces, con tal arreglamento que no se advierta la menor imperfección, como que de ello depende la permanente solidez, y a que debe ocurrirse en tiempo por aquel medio que la afiance con mayor seguridad en su manufactura; y siendo el más seguro el de un determinado precio que se pacte por ajuste, convenio o destajo, con la correspondiente causión de su afiance, pues // de emprenderse la labor en el modo regular por piezas, siendo estas en crecido número, si al tiempo de asentarse descubrieran los defectos de malos ajustes $\mathrm{u}$ otros que las dejaran inútiles, se aventuraba el valor de la piedra, y precio de su manufactura, con otros consecuentes costos, y conferido con el Maestro Mayor don Manuel Álvarez el precio en que debiera ajustarse según su dictamen y bajo las calidades que irán propuestas, se convino el principal otorgante en tomar a su cargo la propuesta construcción en el precio, tiempo, forma, condiciones y circunstancias siguientes:

Primeramente, que dentro de seis meses que comienzan a correr y contarse desde hoy día de la fecha, ha de dar en el todo perfectamente concluída la referida fuente por el precio de dos mil y cuatrocientos pesos que se le han de ir ministrando semanariamente a proporción, y corresponden en las 26 semanas que componen este tiempo a noventa y dos pesos y dos tomines, y en la última un real más; en cuenta de cuyo precio recibe en mi presencia y de los testigos, de que doy fe, de mano de dicho señor Mayordomo Tesorero, cuatrocientos pesos en reales contados a su satisfacción, que pidió y se le entregan adelantados para suplementos a los oficiales, pero bajo de la condición de que ni se le ha de hacer otro suplemento ni se le ha de ministrar en las cuatro semanas siguientes cantidad alguna, de las que a cada una corresponden, hasta la quinta, en que sólo ha de recibir treinta y un pesos que es el exceso que resulta hasta ello, cumplimiento a los cuatrocientos pesos que en este espacio ha de devengar o desquitar.

Item, que ha de labrar las piedras de que se compone el todo y partes de la fuente y pilarejo, arreglado prolija, puntual y pulidamente a la montea o mapa que se halla formado, y se le entrega y recibe, rubricado del presente escribano a satisfacción del Maestro Mayor don Manuel Âlvarez, quien ha de registrar pieza por pieza con cuyo dictamen se le han de recibir o repeler y desechar, no en otra forma.

Item, que ha de poner todo esmero así en el brocal (cuyos resaltos en las partes donde la planta demuestra han de ir tallados únicamente por 
omitirse los intermedios que también manifestaba de talla) como en las estatuas, pedestales y demás follaje, adornos y simetría del pilarejo, sin omitir parte alguna de todas de que se compone, así mayor como menor, siendo de cuenta del otorgante principal la paga y satisfacción de los talladores o estatuarios.

Item, que toda la piedra del brocal, pilarejo y escalones o gradas ha de ser del cerro que nombran del Chiquihuite, de las medidas y tamaños que pudiere el otorgante, a quien se le ha de entregar [a] toda su // satisfacción puestas en el taller, y para que no se suspenda la manufactura ha de avisar y pedir con tiempo las que necesite, de manera que no precediendo el aviso con aquella competente anticipación para el corte, aunque en realidad le falten, no por esto ha de pretender se le descuente el tiempo o tiempos en que la falta se verifique por culpa y omisión del otorgante, porque sin embargo ha de dar cumplimiento dentro del propuesto plazo, y sólo se le descontará cuando con evidencia y sin dolo se le dejaren de entregar las que haya pedido, y que en la propia forma se reconozca las [que] pueden haber hecho falta, y no de otra forma.

Item, que una vez escogidas y electas por el otorgante las piedras aunque después de labradas descubran en lo interior alguna veta, hoja, pelo u otro defecto, por mínimo que sea, si de ello resulta el que pueda temerse o poca permanencia o alguna imperfección, sin más calificación que el sentir del dicho don Manuel Álvarez, no se le han de recibir y ha de volver a labrar a su costa todas las que así se desecharen, satisfaciendo también su corte y conducción, sin que alegue, ni le pueda servir de excepción la nimia proligidad, pues el fin es conseguir la mayor duración, igualdad, limpieza y pulidez; a cuyo efecto le queda el arbitrio de no recibir las que le parezcan y con efecto sean inútiles; bien que tantas cuantas así desechare el otorgante, otras tantas hạ de pedir con la propia anticipación que las demás.

Item, que ha de poner muy particular cuidado y atención en todos y cada uno de los ajustes, engargolando y búscando los enlaces y amarres de las piedras en todo rigor del arte, en cuantas partes lo demandare, sin acomodar pequeñas ni suplir los defectos con semejantes, mayores o menores imperfecciones, pues ninguna se la ha de permitir, antes sí se ha de celar con esmero la más acertada perfección; y este celo se ha de continuar tanto en el taller, cuanto al tiempo de asentarse por el albañil no sólo las piedras de la fuente y pilarejo, sino de las // gradas y ensolado (sic por enlosado?) que ha de ser de la misma piedra y con igual perfección.

$Y$, finalmente, que donde ha de hacer el otorgante la entrega, es en el lugar en que se está concluyendo la fuente como propio para su recibo, y 
en el que se han de ir reconociendo los defectos, para que enmiende los que lo permitieren o labre de nuevo las que no se le admitieren, en inteligencia que ninguna piedra mayor ni menor se le ha de recibir en el taller. Cuyas calidades, condiciones y circunstancias se obligan ambos otorgantes, principal y fiador, en fuerza de la referida mancomunidad, a guardar y cumplir según y en la forma que en todas y cada una se contiene, de manera que se verifiquen precisa y puntualmente, y por su defecto costearán y satisfarán todo aquello en que se verifique no haber dado cumplimiento, exhibiendo en reales de contado bien lo que en el referido suplemento de los cuatrocientos pesos y de otras cantidades se deba devolver, o bien en razón de la manufactura y sus conduscentes costos, conforme a lo que así queda estipulado; 10 que ejecutarán efectiva y llanamente sin contienda de jucio en esta ciudad o en la parte y lugar donde se les pida y demande, y los otorgantes y sus bienes se hallaren, con más las costas y salarios de su cobranza, porque se les pueda ejecutar como por la suerte principal y cantidad líquida, diferido todo en el simple juramento del personero, sin otra prueba de que le releva. Que a su observancia, guarda y cumplimiento, obligan sus personas y bienes habidos y por haber, y con ello se someten al fuero y jurisdicción de los jueces y justicias de Su Magestad que de sus causas conforme a derecho puedan y deban conocer, y especial y señaladamente a las de esta ciudad, corte y Real Audiencia de ella, y al nominado señor superintendente que es o fuere de las referidas obras; renuncian // el suyo propio domicilio y vecindad, la ley si conveneri y las demás de su favor y defensa con la General del Derecho para que se les compelan y apremien como sentencia pasada en autoridad de cosa juzgada.

En cuyo testimonio así lo otorgaron y firmaron, como también lo hicieron dicho señor Mayordomo Tesorero por lo respectivo a la admisión del fiador, y don Manuel Álvarez que intervino en las propuestas condiciones, siendo testigos Ventura de Arellano, Francisco de Torres, vecinos de dicho santuario, y don Thomás de Urioles que lo es de esta ciudad $=$

Br. D. J. de Lizardi y Valle Gerónimo Espinosa Antonio Rodríguez Manuel Álvarez. Ante mi Juan José de Zarazúa, Escribano Real. Sacose día de su otorgamiento en estas tres foxas...

DOCUMENTO 2. Ibidem, f. 207.

Recibí de el señor don Joseph de Lizardi y Valle los dos mil y quatrocientos pesos en reales de contado que expresa esta escritura por haber 
acabado perfectamente la pila con todas las condiciones que se pidieron, y para que conste lo firmé en la ciudad de México, en 10 días de el mes de diciembre de 1752 años, siendo testigos Juan Manuel Guspián y Francisco de Torres y Guerrero.

Antonio Rodríguez

$2,400 \mathrm{p}$. 